\title{
Clinical characteristics, risk factors and angiographic profile of acute coronary syndrome patients in a tertiary care center of Nepal.
}

\author{
Abhishesh Shakya, Sunil Chandra Jha, Ratna Mani Gajurel, Chandra Mani Poudel, Ravi Sahi, Hemant \\ Shrestha, Surya Devkota, Sanjeev Thapa
}

Department of Cardiology, Manmohan Cardio Thoracic Vascular and Transplant Centre (MCVTC), Institute of Medicine, TUTH, Nepal

\author{
Corresponding Author: Abhishesh Shakya \\ Email: avises.shakya@gmail.com \\ Phone no: +9779841759273
}

Cite this article as: Shakya A, Jha S C, Gajurel R M, et al. Clinical characteristics, risk factors and angiographic profile of acute coronary syndrome patients in a tertiary care center of Nepal. Nepalese Heart Journal 2019; Vol 16(1), 27-32

Received date: 2nd February 2019

Accepted date: 30th March 2019

\section{Abstract}

Background and Aims: Acute coronary syndrome (ACS) refers to a group of clinical symptoms consistent with new onset or worsening ischemic symptoms. ST-elevation myocardial infarction (STEMI), non-ST elevation myocardial infarction (NSTEMI) and unstable angina (UA) are the three types of ACS. The objectives were to study the risk factors prevalence, angiographic distribution and severity of coronary artery stenosis in ACS among patients admitted in Cardiology Department of Manmohan Cardiothoracic Vascular and Transplant Center (MCVTC).

Methods: This is a restrospective study of 419 ACS patients admitted and treated in MCVTC from November 2017 to October 2018. Patients were divided into STEMI, NSTEMI and UA then analyzed for various risk factors, angiographic patterns and severity of coronary artery disease.

Results: Mean age of presentation was $59.3 \pm 12.8$ years. Majority were male $317(75.7 \%)$. Most patients had STEMI 252 (60.1\%) followed by NSTEMI 98 (23.4\%) and UA 69 (16.5\%). Risk factors: smoking was present in 241 (57.5\%), hypertension in $212(50.6 \%)$, diabetes in $144(34.4 \%)$, dyslipidemia in $58(13.8 \%)$. Single-vessel disease was present in $34.6 \%$ patients, double- vessel disease was present in $27.44 \%$ patients and triple vessel disease was present in 26.3 $\%$ patients, left main disease in $1.4 \%$ patients. Normal coronaries were present in $6.4 \%$ patients and minor coronary artery disease in $3.8 \%$ patients.

Conclusions: STEMI was the most common presentation. Three quarters of ACS were male patients. Smoking was most prevalent risk factor. Single vessel involvement was the most common CAG finding in all spectrum of ACS. Diabetic patients had more multivessel disease.

Keywords: Acute Coronary Syndrome, Angiogram, Nepal.

DOI: https://doi.org/10.3126/njh.v16i1.23895

\section{Introduction}

Ischemic heart disease (IHD) is the most common cause of mortality worldwide with over 7 million deaths annually. ${ }^{1} \mathrm{It}$ is estimated that $32 \%$ of all death will be due to CAD and it will be the leading cause of disability ${ }^{2}$ worldwide by 2020 . The term acute coronary syndrome (ACS) refers to a group of clinical symptoms consistent with new onset or worsening ischemic symptoms and includes the spectrum of clinical conditions ranging from unstable angina (UA) to non-ST-segment elevation myocardial infarction (NSTEMI) and ST-segment elevation myocardial infarction (STEMI). Unstable angina and NSTEMI are closely related conditions: their pathophysiologic origins and clinical presentations are similar, but they differ in severity. ${ }^{3}$ The proportion of ACS types varies across various studies with decrease in the STEMI compared to NSTEMI owing to development of more sensitive markers of myocardial injury. ${ }^{4}$ Each year in the United States alone, approximately 1.36 million hospitalizations are required for ACS (listed either as a primary or a secondary discharge diagnosis), of which 0.81

@Nepalese Heart Journal. Nepalese Heart Journal retains copyright and work is simultaneously licensed under Creative Commons Attribution License CC - BY 4.0 that allows others to share the work with an acknowledgement of the work's authorship and initial publication in this journal. 
million are for myocardial infarction (MI) and the remainder are for UA. Roughly two-thirds of patients with MI have NSTEMI; the rest have STEMI ${ }^{5}$. While ACS has always been a significant health problem in the developed world, it has become more difficult for developing South Asian country like Nepal to cope with the rising burden of the disease. Meanwhile, we have limited data on the nature and distribution of ACS. ${ }^{6-10}$

The objectives of this retrospective study were to study the clinical profile, prevalence of risk factors and distribution of coronary artery stenosis in ACS patients admitted in Cardiology Department of MCVTC.

\section{Methods}

This is a retrospective study carried out in Manmohan Cardiothoracic Vascular and Transplant Center (MCVTC) from November 1, 2017 to October 31, 2018. After taking clearance from Institutional Review Board, 419 patients who presented to Cardiology Department of MCVTC in last one year with first episode of ACS undergoing coronary angiography were analyzed The clinical presentations of patient were categorized as NSTEMI and STEMI according to American College of Cardiology/American Heart Association (ACC/AHA) definitions and treated as per ACC/AHA recommendations. ${ }^{11,12}$

\section{Inclusion Criteria:}

1. All patients fulfilling diagnostic criteria for ACS.

2. Age $\geq 18$ years.

\section{Exclusion Criteria}

1. Previous angina, angina equivalent or MI or coronary revascularization (more than two weeks old).

2. Patients with prior cardiac pathology like valvular heart disease, cardiomyopathy, pericardial disease or cor pulmonale.

Medical records were reviewed which included medical history, physical examination, age, gender, CAD risk factor profile, smoking history, lipid profile, fasting blood sugar, HbA1C levels, ECG, echocardiography and coronary angiography.

Dyslipidemia was defined as the presence of any of the following: patients on lipid lowering drugs or total cholesterol $>240 \mathrm{mg} / \mathrm{dl}$, triglycerides (TG) $>150 \mathrm{mg} / \mathrm{dl}$, low-density lipoprotein $>130 \mathrm{mg} / \mathrm{dl}$, and high-density lipoproteins (HDL) $<50 \mathrm{mg} / \mathrm{dl}$ for female and $<40 \mathrm{mg} / \mathrm{dl}$ for male. ${ }^{13}$

Diabetes Mellitus was defined as symptoms of diabetes, fasting blood sugar $>126 \mathrm{mg} / \mathrm{dl}(7.0 \mathrm{mmol} / \mathrm{L})$ or $\mathrm{HbAlC}$ level $>$ 6.5 or if patient was on oral hypoglycemic agents. ${ }^{14}$

Hypertension was defined as systolic blood pressure $>140$ and/or diastolic $>90 \mathrm{mmHg}$ and/or on anti-hypertensive treatment. ${ }^{15}$

Positive family history was considered if first degree relatives had CAD before the age of 55 years in men and 65 years in women. ${ }^{13}$

Significant CAD was defined as a diameter stenosis $>50 \%$ in each major epicardial artery. Normal vessels were defined as the complete absence of any disease in the left main coronary artery (LMCA), left anterior descending (LAD), right coronary artery (RCA), and left circumflex (LCX) as well as in their main branches (diagonal, obtuse marginal, ramus intermedius, posterior descending artery, and posterolateral branch). Patients were classified as having single-vessel disease (SVD), doublevessel disease (DVD) or triple vessel disease (TVD) accordingly.

\section{Statistical Analysis}

The results were reported as mean and standard deviation for the quantitative variables and percentages for the categorical variables. The groups were compared using the Student's t-test for the continuous variables and the Chi-square test for the dichotomous variables. $\mathrm{P}<0.05$ were considered as statistically significant. All the statistical analyses were carried out via Statistical Package for Social Sciences version 20 (SPSS, IL, Chicago Inc., USA).

\section{Results}

Among 419ACS patients, majority were male 317 (75.7\%) and $192(24.3 \%)$ were female (Fig 2). The mean age of presentation was $59.3+/-12.8$ years. Mean age of female and male patients was $61.75+10.85$ and $58.5+13.35$ years respectively. fifty six \% of patients were above 60 years. fourteen \% of patients were below 45 years (Fig 4). Most common presentation in ACS was STEMI with $252(60.1 \%)$ patients followed by NSTEMI 98 (23.4\%) and UA $69(16.5 \%$ ) ( Fig 3). Baseline characteristics are mentioned in Table I.

Table-I : Baseline characteristics of the study population $(\mathrm{N}=419)$

\begin{tabular}{|l|l|l|l|l|}
\hline & Minimum & Maximum & Mean & $\begin{array}{l}\text { Std. } \\
\text { Deviation }\end{array}$ \\
\hline Age & 23.0 & 90.0 & 59.30 & 12.85 \\
\hline $\begin{array}{l}\text { Fasting blood } \\
\text { sugar (mg/dl) }\end{array}$ & 56.0 & 299.0 & 123.00 & 40.59 \\
\hline HbA1C & 4.3 & 12.4 & 6.27 & 1.56 \\
\hline $\begin{array}{l}\text { Creatinine } \\
\text { (mg/dl) }\end{array}$ & .45 & 7.0 & .92 & .41 \\
\hline Triglyceride & 34.0 & 777.0 & 143.11 & 86.12 \\
\hline $\begin{array}{l}\text { Total } \\
\text { cholesterol }\end{array}$ & 11.0 & 568.0 & 144.70 & 49.38 \\
\hline HDL & 15.0 & 79.0 & 38.16 & 10.48 \\
\hline LDL & 19.0 & 275.0 & 91.13 & 35.56 \\
\hline LVEF & 20.0 & 70.0 & 49.66 & 11.24 \\
\hline
\end{tabular}

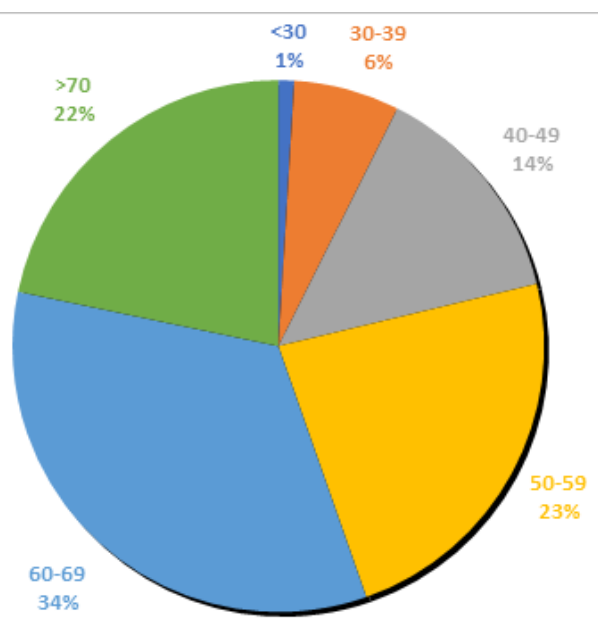

Fig.-1: Age distribution of study population 


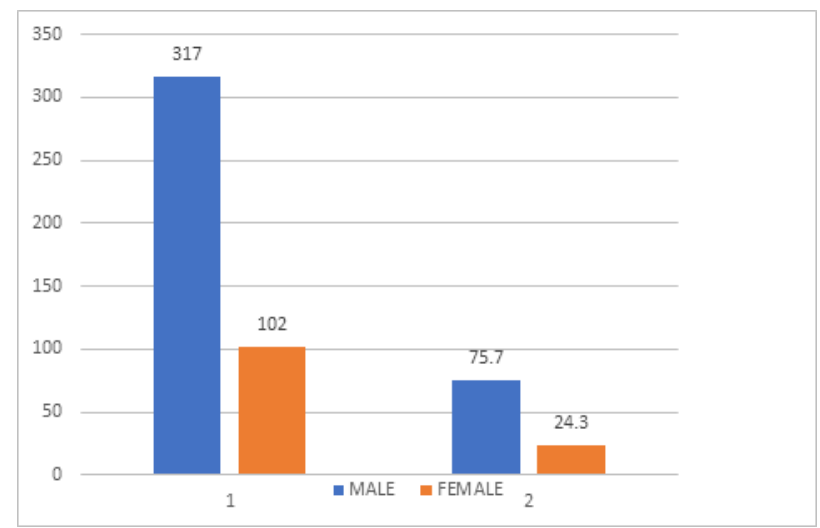

Fig.-2: Distribution of study population according to sex $(\mathrm{N}=419)$, 1 denotes total number of patients, 2 denotes percentage of patients.

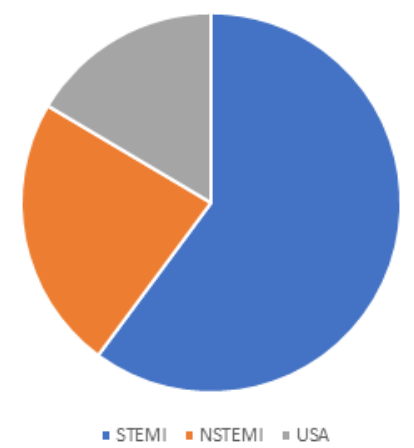

Fig.-3: Distribution of study population according to type of ACS

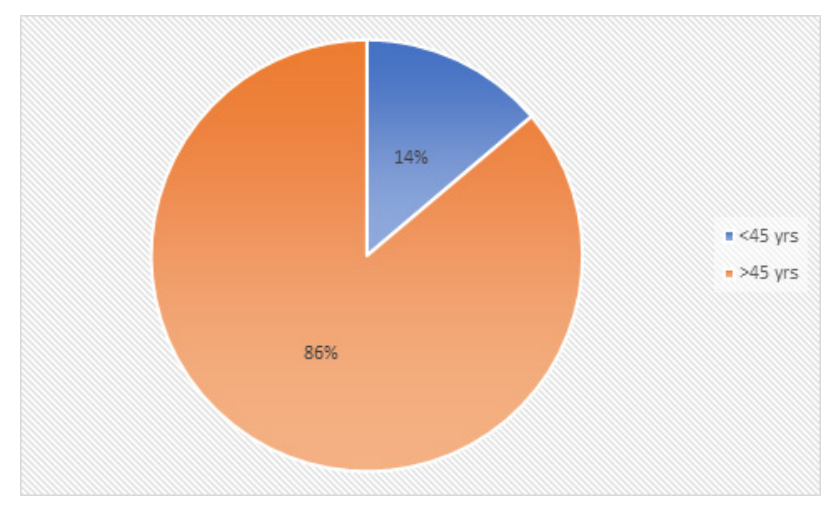

Fig.-4: Proportion of young ACS patients

\section{Risk factors analysis}

A total of 144 (34.4\%) patients were diabetic and $212(50.6 \%)$ patients were hypertensive. Smoking was the most prevalent risk factor found in $241(57.5 \%)$ patients. Dyslipidemia was present in $58(13.8 \%)$ patients. Family history of CAD was significant in $11(2.6 \%)$ patients. Table II

Table-II : Distribution of study population according to clinical risk factors

\begin{tabular}{|l|l|l|}
\hline Clinical Risk factor & Frequency & Percent (\%) \\
\hline Smoking & 241 & 57.5 \\
\hline Diabetes Mellitus & 144 & 34.4 \\
\hline
\end{tabular}

\begin{tabular}{|l|l|l|}
\hline Hypertension & 212 & 50.6 \\
\hline Dyslipidemia & 58 & 13.5 \\
\hline Family History & 11 & 2.6 \\
\hline
\end{tabular}

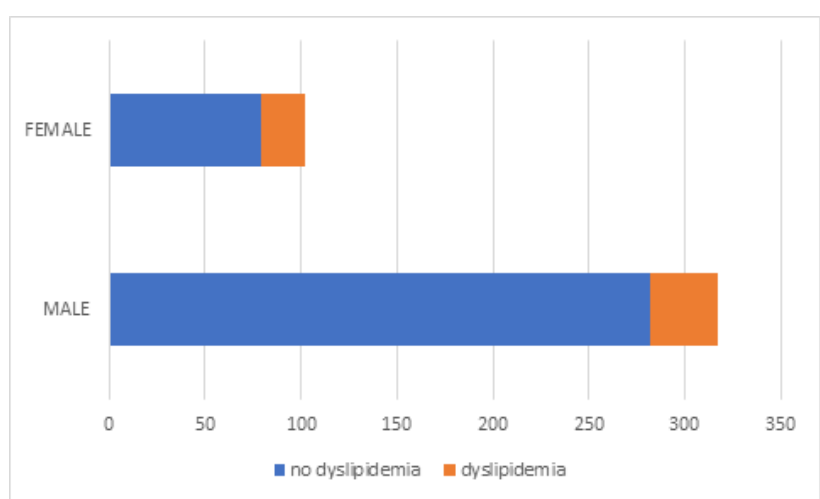

Fig.-5: Distribution of dyslipidemia according to sex

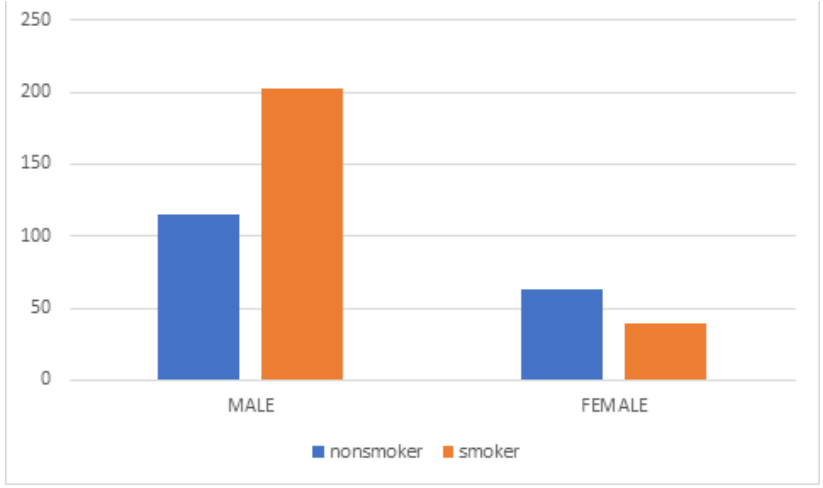

Fig.-6: Distribution of smoking according to sex

Dyslipidemia was seen significantly higher in female population $22.5 \%$ compared to male $11 \%$ ( $=0.003$ ) (Fig 5). Smoking was significantly higher in male population $63.7 \%$ compared to female $38.2 \%(\mathrm{p}=0.0001)$ ( Fig 6). However, there was no gender difference in prevalence of Diabetes mellitus, hypertension and family history of coronary artery disease.

\section{Angiographic profile}

Overall, SVD was seen in $34.6 \%$ patients, DVD in $27.44 \%$ patients, TVD in $26.3 \%$ patients, left main disease in $1.4 \%$ patients, normal coronary vessels in $6.4 \%$ and nonsignificant lesion were seen in $3.8 \%$ patients out of 419 patients (Fig 7). In STEMI, SVD was seen in 102 (40.4\%), DVD in 76 (30.1\%), TVD in $70(27.8 \%)$, Left Main disease in 3 (1.2\%) and Minor lesion in 1 patient. In NSTEMI, SVD was seen in $23(23.4 \%)$, DVD in $23(23.4 \%)$, TVD in 34(34.7\%), left main disease in $3(3$ $\%)$, minor lesion in $9(9.2 \%)$ and normal coronaries in 8 (8.2\%). In UA, SVD was seen in 20(28.9\%), DVD in $16(23.2 \%)$, TVD in $6(8.7 \%)$, Left Main disease in 2(2.9\% ), Minor Lesion in $6(8.7$ $\%$ ) and Normal coronaries in 19 (28.36\%) (Fig 8). This showed greater incidence of insignificant lesions or normal coronaries in UA followed by NSTEMI. 


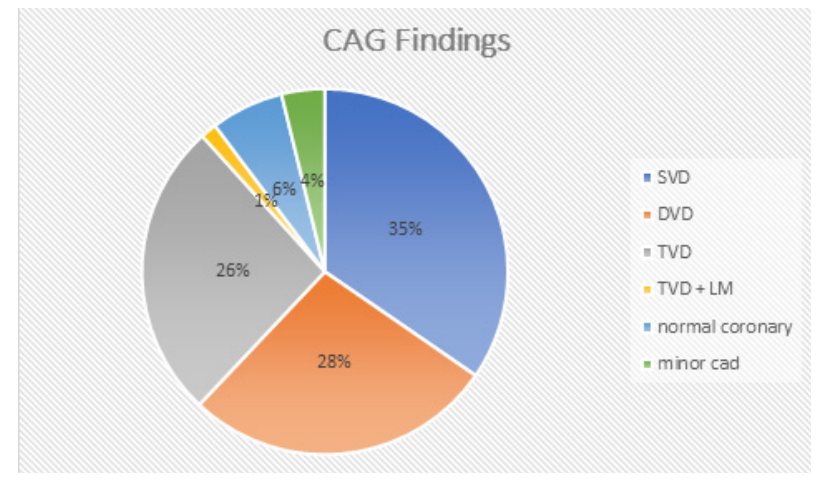

Fig.-7: Distribution of study population according to CAG findings.

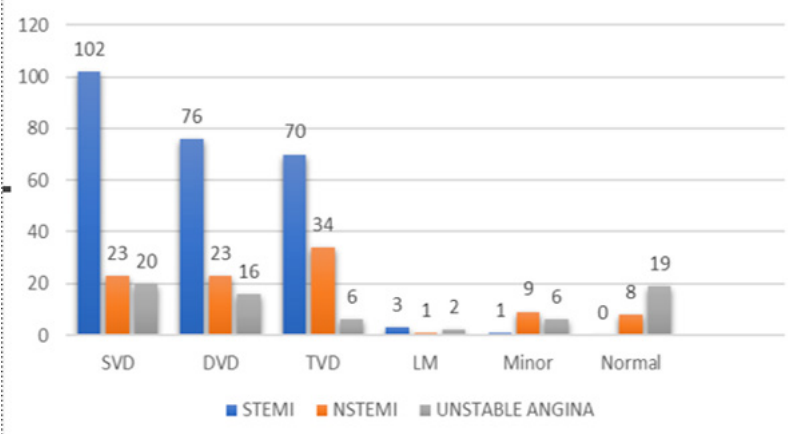

Fig.-8: Distribution of study population according to extent of disease

Of 317 male patients,199 (62.8\%) were STEMI and 118 (37.2\%) were NSTEMI and UA combined. Whereas in 102 female patients 53 (52 \%) were STEMI and 49 (48\%) NSTEMI and UA combined. This showed gender difference in the presentation of ACS ( $p=0.05$ ) (Fig 9) However, there was no gender difference in the number of vessels involved $(\mathrm{p}=0.4 \%)$

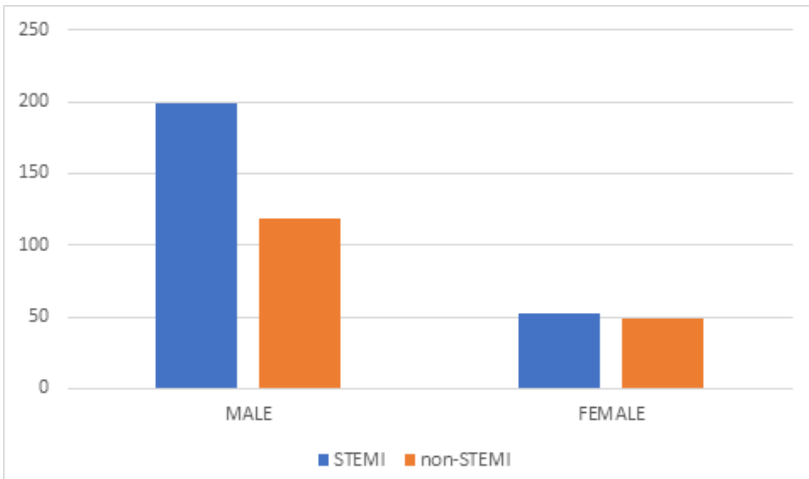

Fig.-9: Distribution of ACS according to sex

Of the risk factors, diabetic patients were more likely to have triple vessel disease compared to non-diabetics $52(36.1 \%)$ vs 64 $(23.2 \%)(\mathrm{p}=0.005)($ Fig 10$)$

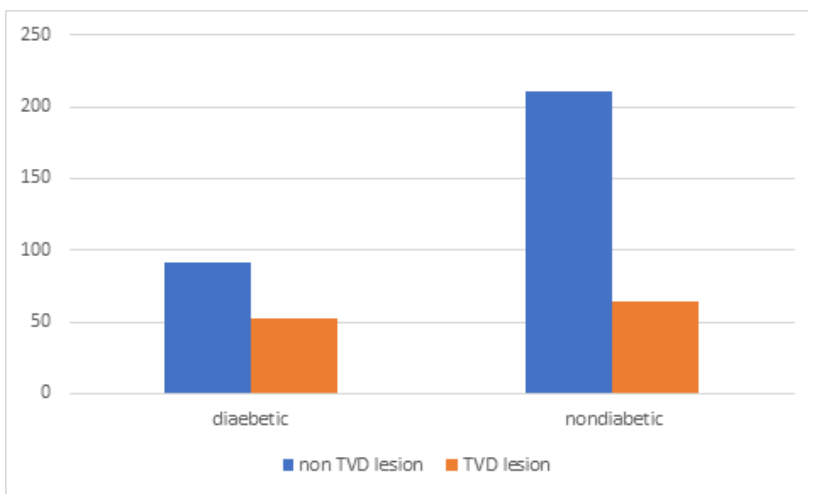

Fig.-10: Distribution of CAG findings in Diabetic population

In one case of STEMI there was completely normal CAG findings that was due to autothrombolysis.

\section{Discussion}

South Asia comprise around one quarter of world population and are at high risk of developing CAD. ${ }^{16}$ As per Global Burden of Disease (GBD) 2010, CAD deaths have drastically increased in this region by $87 \%$ between 1990 to 2010 second only to East Asia. ${ }^{18,19}$ This is predicted to increase a further $50 \%$ by $2030 .{ }^{1}$ According to the latest WHO data published in 2017 Coronary Heart Disease deaths in Nepal reached 30,559 or $18.72 \%$ of total deaths. The age adjusted Death Rate is 158.35 per 100,000 of population which ranks Nepal as 41 st in the world. ${ }^{17}$

This retrospective study was carried out at the department of Cardiology, MCVTC November 1, 2017 to October 31, 2018. The mean age of the study population was $59.3+12.8$ years as compared to $60+12$ years in a study by Mohanan et $\mathrm{al}^{20}, 58+11$ years by Sahed et al in Pakistan ${ }^{21}, 51+8.80$ years by Ahmed et $\mathrm{al}^{22}$ in Bangladesh and $62+5$ years in COURAGE trial ${ }^{23}$ conducted in the USA. fifty six percent of patients were above 60 years and 14 $\%$ of patients were below 45 years and $21 \%$ were below 50 years compared to $27 \%$ in a study by Agrawal et al. ${ }^{24}$

Overall, women were older with female age of $61.75+10.85$ years vs male age of $58.5+13.35$ years compared to $66.41+13.1$ years vs $52.49+11.7$ years in a study by Singh et $\mathrm{al}^{25}$ and $70.7+12.7$ years vs $63.8+12.9$ years in a study by Isorni et al. ${ }^{26}$

Among 419 patients, majority of the patients were male $(75.7 \%)$ and only $24.7 \%$ were female. This is as seen in INTERHEART study ${ }^{27}$ and its South Asian Cohort (Overall Male $76 \%$ and $85 \%$ in South Asian Male)

Smoking is an established risk factor for Coronary Artery Disease. In our study, smoking was the most prevalent risk factor found in $241(57.5 \%)$ patients. Smoking was significantly higher in male population $63.7 \%$ compared to female $38.2 \%$ $(\mathrm{p}=0.0001)$. This is similar to study done in $\mathrm{Pakistan}^{28}$ where $52 \%$ were smoker and male were more likely to be smoker compared to female.

Followed by smoking, hypertension was the most common risk factor with 212(50.6\%) patients being hypertensive. The prevalence of hypertension in the South Asian Cohert of INTERHEART Study ${ }^{27}$ was $31.1 \%$ which is much lower than our study. However, studies done in India ${ }^{29}$ and Pakistan ${ }^{28}$ showed $48 \%$ and $55 \%$ respectively which is similar to our study. 
Diabetes is another important risk factor which was found in $34.4 \%$ of study population. This was again higher than shown by INTERHEART study ${ }^{27}$ in South Asian Cohort but similar to South Asian Studies. Study in Bangladesh ${ }^{22}$ showed 29\% of ACS patients were diabetics. Similarly, another study in North India ${ }^{29}$ showed $40 \%$ prevalence of Diabetes in ACS patients.

Of the risk factors, diabetic patients were more likely to have triple vessel disease compared to non-diabetics (36.1\% vs 23.27$)$ $(\mathrm{p}=0.005)$. Similar result was seen in a study by Gui et $\mathrm{al}^{30}$ in China and Kumar et $\mathrm{a}^{29}$ in India. This relatively higher prevalence of Triple Vessel Disease in diabetic population compared to nondiabetics proves diabetes is an important chronic risk factor for CAD.

Dyslipidemia is another important risk factor which was present in $58(13.8 \%)$ patients. Dyslipidemia was seen significantly higher in female population $(22.5 \%$ compared to male $11 \%(\mathrm{p}=0.003))$ similar to that found in a study done in Bangladesh $^{31}$.

Around $60 \%$ of our ACS patients were STEMI followed by NSTEMI (23.4\%) and UA (16.5\%). This finding is similar to that seen in Indian studies ${ }^{32}$ where STEMI is predominant. This is different to European studies where NSTEMI predominates. ${ }^{33-35}$ STEMI was the most common presentation in both sexes. However, NSTEMI and UA were more common in female than in male counterpart with statistical significance $(p=0.05)$. This was similar to another study by Isorni et al. ${ }^{26}$

\section{Angiographic profile}

Single-vessel involvement was the most common in all groups of ACS (34.6\%) including UA, NSTEMI and STEMI, followed by double-vessel $(27.44 \%)$ and triple vessel disease $(26.3 \%)$ and left main disease in $1.4 \%$ patients. Akanda et $\mathrm{al}^{36}$ also showed more single vessel involvement. Similarly, Kumar et $\mathrm{al}^{29}$ and Tewari et ${ }^{37}$ al also similar finding

Angiographically, absolutely normal vessels were present in $6.4 \%$ and minor coronary artery disease was seen in $3.8 \%$ patients which was more prevalent in UA followed by NSTEMI. Angiographically normal coronary was seen in $14 \%$ cases of ACS in a study by Ahmed et $\mathrm{a}^{22}$. In UA, many patients may have been over diagnosed and so were false positive. Similarly, false positive cases in NSTEMI may be attributed to other causes of raised troponin levels apart from myocardial infarction like myocarditis, infection with sepsis and renal impairment. ${ }^{38}$

\section{Study Limitations}

Our study was a single center, retrospective and observational analysis. This can be associated with selection bias and missing information. No follow up data was presented as this study was based only on in-hospital records.

\section{Conclusion}

$\mathrm{CAD}$ is a major health challenge for us. Despite decrease in cardiovascular disease mortality in developed countries, substantial increases have been experienced in developing countries like ours. In our study population, there was male preponderance. STEMI was the most common presentation of ACS which is different from the European study where NSTEMI is common. Smoking is the most common risk factor followed by hypertension and diabetes mellitus. Single vessel disease was the most common CAG finding irrespective of type of ACS. Diabetic patients had more multivessel CAD compared to non-diabetics. Nation-wide research should be done to determine the different aspects of CAD in Nepal so as to estimate the magnitude of problem it bears on overall health of the people. Primary and secondary prevention strategies should be vigorously pursued.

\section{References}

1. Mathers CD, Loncar D. Projections of global mortality and burden of disease from 2002 to 2030. PLoS Med. 2006;3(11):e4421WHO 2017. The top 10 causes of death. Available at:

https://doi.org/10.1371/journal.pmed.0030442

2. Murray CJ, Lopez AD. Mortality by cause for eight regions of the world: Global Burden of disease study. Lancet 1997; 349: $1269-1276$. https://doi.org/10.1016/S0140-6736(96)07493-4

3. Gazanio TA, Gazanio JM. Global burden of cardiovascular disease 'In: RO. Bonow, DL. Mann, DPZipes, P. Libby, 9th ed. Braunwald Heart disease:A text book of cardiovascular medicine. Missouri:Elsvier, Saunders. 2011:1-20.

4. Benjamin EJ, Blaha MJ, Chiuve SE et al. Heart disease and stroke statistics-2017 update. A report from American Heart Association. Circulation. 2017;135 (10):e146-e606. https://doi.org/10.1161/CIR.0000000000000491

5. Lloyd-Jones D, Adams R, Carnethon M, et al. American Heart Association Statistics Committee and Stroke Statistics Subcommittee Heart disease and stroke statistics-2009 update. a report from the American Heart Association Statistics Committee and Stroke Statistics Subcommittee [published correction appears in Circulation. 2009;119(3):e182] Circulation 2009 January27; 119(3):480486 Epub 2008 Dec 15.

https://doi.org/10.1161/circulationaha.108.191259

6. Shreshta NR, Basnet S, Bhandari R et al .Presentation and outcome of patients with acute coronary syndromes in eastern Nepal. Swiss Med Wkly. 2011 Apr 13;141:w13174. doi: 10.4414/smw.2011.13174. eCollection 2011. https://doi.org/10.4414/smw.2011.13174

7. Gautam MP, Sogunuru G, Subramanyam G, et al. Acute coronary syndrome in an intensive care unit of a tertiary care centre: the spectrum and coronary risk factors. J Nepal Med Assoc. 2013 Apr-Jun;52(190):316-21.

https://doi.org/10.31729/jnma.1897

8. Chhetri BK, Paudel MS, Dhungana SP et al. Clinical profile of patients with acute coronary syndrome in Lumbini Medical College and Teaching Hospital: A prospective study. Journal of Lumbini Medical College. Dec 30, 2013. https://doi.org/10.22502/jlmc.v1i1.3

9. Laudari S, Dhungel S, Dubey L et al. Acute coronary syndrome in the young Nepalese population with their angiographic characteristics. Journal of College of Medical Sciences-Nepal, Vol-13, No 2, Apr-June 017. https://doi.org/10.3126/jcmsn.v13i2.17147

10. Paudel N, Alurkar VM, Jha GS et al. Profile of acute coronary syndrome in young people: a hospital based observational study in western nepal. Birat journal of health sciences. vol.3/no.1/issue 5/ jan-april 2018.

https://doi.org/10.3126/bjhs.v3i1.19759

11. Thygesen K, Alpert JS, Jaffe AS, et al. Fourth Universal Definition of Myocardial Infarction (2018). J Am Coll Cardiol 2018; 72:2231.

https://doi.org/10.1016/j.jacc.2018.08.1038

12. ACC/AHA 2007 Guidelines for the Management of Patients With Unstable Angina/Non-ST-Elevation Myocardial Infarction

13. Third Report of the National Cholesterol Education Program (NCEP) Expert Panel on Detection, Evaluation, and Treatment of High Blood Cholesterol in Adults 
(Adult Treatment Panel III) Executive Summary. National Cholesterol Education Program National Heart, Lung, and Blood Institute National Institutes of Health NIH Publication No. 01-3670 May 2001.

https://doi.org/10.1001/jama.285.19.2486

14. American Diabetes Association. Diabetes Care 2018 Jan; 41(Supplement 1): S13-S27

15. Thomas L, Schwenk, MD and Thomas L, et al. JAMA 2003 May 21. New Hypertension Guidelines: JNC 7

16. Lozano R, Naghavi M, Foreman K et al. Global and regional mortality from 235 causes of death for 20 age groups in 1990 and 2010: a systematic analysis for the Global Burden of Disease Study 2010. Lancet. 2012;380(9859):2095-2128. https://doi.org/10.1016/S0140-6736(12)61728-0

17. World Health Rankings 2017. World Health Organisation

18. Joshi P, Islam S, Pais P, et al. Risk factors for early myocardial infarction in South Asians compared with individuals in other countries. JAMA 2007;297(03):286-294.

https://doi.org/10.1001/jama.297.3.286

19. Yusuf S, Reddy S, Ônpuu S, et al. Global burden of cardiovascular diseases part I: general considerations, the epidemiologic transition, risk factors, and impact of urbanization. Circulation 2001:104(22):2746-2753. https://doi.org/10.1161/hc4601.099487

20. Mohanan PP, Mathew R, Harikrishnan S, et al. Presentation, management, and outcomes of 25748 acute coronary syndrome admissions in Kerala, India: results from the Kerala ACS Registry.

21. Hafeez S, Javed A, Kayani AM. Clinical profile of patients presenting with ST elevation Myocardial Infarction. JPMA 2010;60:190.

22. Ahmed M, Rubaiyat KA, Mohammed Abaye, et al. Clinical Characteristics and Angiographic Profile of Acute Coronary Syndrome Patients in a Tertiary Hospital of Bangladesh. Bangladesh Heart Journal 2018; 33. https://doi.org/10.3329/bhj.v33i1.37018

23. Boden WE, O'rourke RA, Teo KK, et al .COURAGE Trial Co-Principal Investigators and Study Coordinators. The evolving pattern of symptomatic coronary artery disease in the United States and Canada: baseline characteristics of the Clinical Outcomes Utilizing Revascularization and Aggressive DruG Evaluation (COURAGE) trial.

24. Agrawal V, Lohiya BV, Sihag BK, et al. Clinical Profile with Angiographic Correlation in Naïve Acute Coronary Syndrome Journal of Clinical and Diagnostic Research. 2016 Sep, Vol-10(9): OC10-OC14. https://doi.org/10.7860/JCDR/2016/21166.8519

25. Singh Y, Satyawali V, Joshi A, et al.The Clinical Spectrum of Acute Coronary Syndromes: A study from tertiary Care center of Kumaun Region of Uttarakhand. Nigerian Journal of Cardiology, Year : 2014 | Volume: 11 | Issue Number: 1 | Page: 27-32. https://doi.org/10.4103/01897969.130076

26. Isorni MA, Blanchard D, Teixeira $\mathrm{N}$, et al.Impact of gender on use of revascularization in acute coronary syndromes: The national observational study of diagnostic and interventional cardiac catheterization (ONACI) Catheterization and Cardiovascular Interventions 2:E5865 - August 2015 DOI: $10.1002 / \mathrm{ccd} .25921$. https://doi.org/10.1002/ccd.25921

27. Yusuf S, Hawken S, Ounpuu S, et al. Effect of potentially modifiable risk factors associated with myocardial infarction in 52 countries (the INTERHEART study): Case- controlstudy. Lancet 2004;364:937-952. https://doi.org/10.1016/S0140-6736(04)17018-9
28. Maqbool H, Jafary, Abdus Samad, et al. Profile of Acute Myocardial Infarction in Pakistan. Pak J Med JulySeptember 2007. Vol. 23 No.4 485-489

29. Kumar N, Sharma S, Mohan B, et al. Clinical and angiographic profile of patients presenting with first acute myocardial infarction in a tertiary care center in northern India. Indian Heart J. 2008 May-Jun;60(3):210-214.

30. Gao X, Gui MH, Qin GY, et al. The comaparsion of coronary angiographic profiles between diabetic and nondiabetic patients with coronary artery disease in a Chinese population. Diabetes Research and Clinical practice. August 2009 Volume 85,Issue 2,Pages 213-219. https://doi.org/10.1016/j.diabres.2009.05.010

31. Islam, A, Faruque, M, Chowdhury A, et al. Risk factor Analysis and Angiographic Profiles in First 228 Cases Undergone Coronary Angiography in Cardiac Cath Lab of Dhaka Medical College Hospital. Cardiovascular Journal, 3(2), 122-125. https://doi.org/10.3329/cardio.v3i2.9179

32. Sharma R, Bhairappa S, Prasad SR, et al. Clinical characteristics, angiographic profile and in hospital mortality in acute coronary syndrome patients in south indian population. Heart India Year : 2014 | Volume : 2 | Issue : 3 । Page : 65-69.

https://doi.org/10.4103/2321-449X.140228

33. Steg PG, Goldberg RJ, Gore JM, et al. Baseline Characteristics, Management Practices, and In-Hospital Outcomes of Patients Hospitalized With Acute Coronary Syndromes in the Global Registry of Acute Coronary Events (GRACE). Am J Cardiol. 2002;90:358-363. https://doi.org/10.1016/S0002-9149(02)02489-X

34. Hasdai D, Behar S, Wallentin L, et al. A prospective survey of the characteristics, treatments and outcomes of patients with acute coronary syndromes in Europe and the Mediterranean basin. The Euro Heart Survey of Acute Coronary Syndromes (Euro Heart Survey ACS). Eur Heart J. 2002;23:1190-1201. https://doi.org/10.1053/euhj.2002.3193

35. Mandelzweig L, Battler A, Boyko V, et al. The second Euro Heart Survey on acute coronary syndromes: characteristics, treatment, and outcome of patients with ACS in Europe and the Mediterranean Basin in 2004. Eur Heart J. 2016;27(19):2285-2293. https://doi.org/10.1093/eurheartj/ehl196

36. Akanda MAK, Ali SY, Islam AEMM, et al. Demographic Profile,Clinical Presentation \& Angiographic Findings in 637Patients with Coronary Heart Disease. Faridpur Medical College Journal 2011; 6(2):82-85. https://doi.org/10.3329/fmcj.v6i2.9206

37. Tewari S, Kumar S, Kapoor A, et al. Premature coronary artery disease in North India: An angiography study of 1971 patients. Indian Heart J 2005;57:311-318.

38. Korff S, Katus HA, and Giannitsis E Differential diagnosis of elevated troponins. Heart. 2006 Jul; 92(7): 987-993. doi: $10.1136 /$ hrt.2005.071282 